\title{
Painful Knee Arthroplasty
}

\author{
Katie Traylor, Prashant Jolepalem, and Paresh Mahajan \\ Department of Diagnostic Radiology and Molecular Imaging, William Beaumont Health System, Royal Oak, Michigan
}

\begin{abstract}
A triple-tracer nuclear medicine study that incorporates ${ }^{99 m} \mathrm{Tc}-$ sulfur colloid, ${ }^{111} \mathrm{In}$-labeled leukocytes, and $99 \mathrm{~m}$ Tc-methylene diphosphonate can be useful for the diagnosis of aseptic loosening in a patient after total-knee arthroplasty, as demonstrated in this case study. The triple-tracer technique takes less time and is more accurate than a bone scan alone.
\end{abstract}

Key Words: bone; instrumentation; joint/muscle; ${ }^{111}$ In-labeled autologous leukocytes; ${ }^{99 m T c-M D P ; ~}{ }^{99 m T c}$-sulfur colloid

J Nucl Med Technol 2014; 42:122-123

DOI: 10.2967/jnmt.113.132753

$\mathbf{T}$ his article discusses the importance of the use of a tripletracer study in the postoperative knee to diagnose an aseptic knee. The components of the triple tracer will be discussed, as well as how the results of this study can aid the orthopedic surgeon in designing a treatment plan that will be successful for the patient. knee pain, which did not improve with conservative management. She had undergone cemented total-right-knee arthroplasty 2 y previously for osteoarthritis. She was previously pain-free and had not undergone recent trauma. She was afebrile and had a mildly elevated white blood cell count of 10.7 billion/L. A triple-tracer study was requested to evaluate for septic prosthesis loosening.

The patient was first injected with $373.7 \mathrm{MBq}(10.1 \mathrm{mCi})$ of ${ }^{99 \mathrm{~m}} \mathrm{Tc}$-sulfur colloid, and spot views of the knees were obtained. The patient was then injected with $20.72 \mathrm{MBq}$ $(0.56 \mathrm{mCi})$ of ${ }^{111} \mathrm{In}$-labeled leukocytes, and similar-projection 24-h delayed images of the knees were obtained. Lastly, the patient was injected with $862.1 \mathrm{MBq}(23.3 \mathrm{mCi})$ of ${ }^{99 \mathrm{~m}} \mathrm{Tc}$-methylene diphosphonate, and acquisition of dynamic flow and static blood-pool images followed immediately afterward. After 3-4 h of tracer localization, spot views of the knees were obtained.

Comparison of the ${ }^{99 \mathrm{~m}} \mathrm{Tc}$-sulfur colloid and ${ }^{111} \mathrm{In}$-labeled leukocyte images (Fig. 1) did not demonstrate discordant uptake of the latter to suggest infection. On the 3-phase

FIGURE 1. Anterior/posterior (left) and medial/lateral (right) projection images of knees after injection with ${ }^{99 m T c-s u l f u r ~ c o l l o i d . ~}$

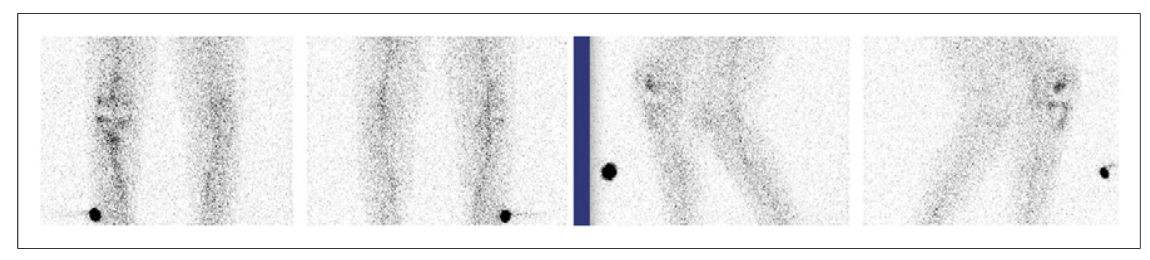

FIGURE 2. Anterior/posterior (left) and medial/lateral (right) projection images of knees after injection with ${ }^{111}$ In-labeled autologous leukocytes.

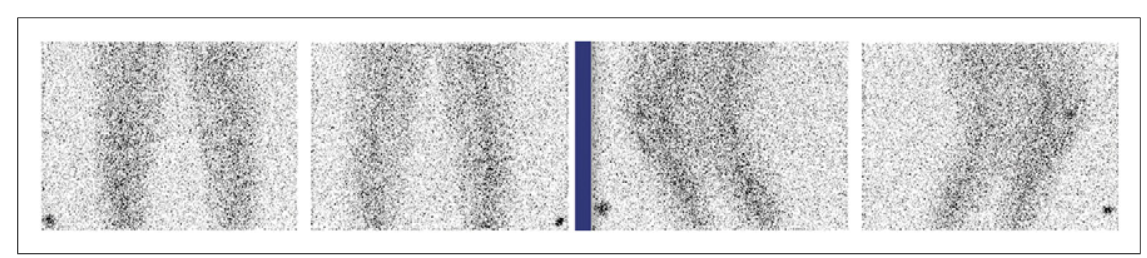

\section{CASE REPORT}

A 59-y-old woman with a history of rheumatoid arthritis and osteoarthritis presented with 6 mo of progressive right

Received Sep. 17, 2013; revision accepted Nov. 24, 2013.

For correspondence or reprints contact: Katie Traylor, William Beaumont Hospital, 3601 W. Thirteen Mile Rd., Royal Oak, MI 48073.

E-mail: katietraylordo@gmail.com

Published online Mar. 13, 2014.

COPYRIGHT (C 2014 by the Society of Nuclear Medicine and Molecular Imaging, Inc. 99m Tc-methylene diphosphonate bone scan, there was periprosthetic hyperemia near the tibial component on the early images (Fig. 2). On the delayed images, there was increased uptake at the interface between the tibial plateau native bone and the prosthesis, worse medially (Fig. 3).

The triple-tracer findings were consistent with aseptic failure of the prosthesis. Surgical exploration did not reveal any signs of infection; however, the tibial component had subsided into the medial tibial plateau and was easily 


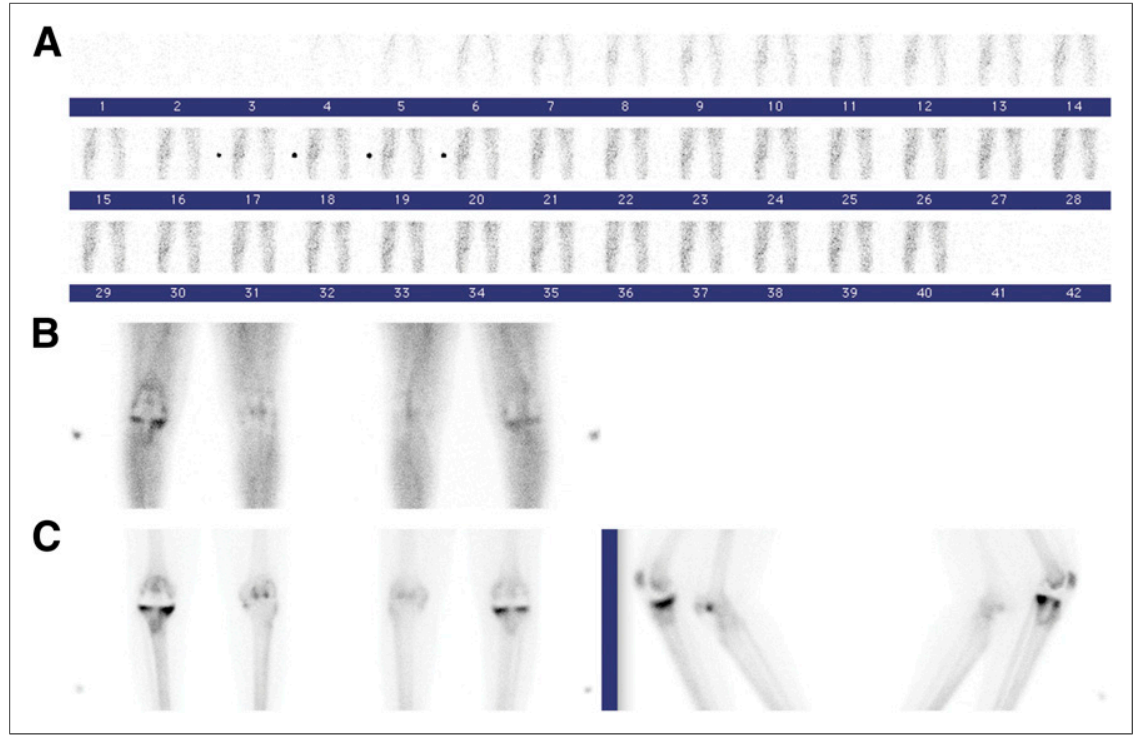

FIGURE 3. (A) Anterior projection bloodflow images with right-sided marker. (B) Blood-pool 99mTc-methylene diphosphonate images of knees in anterior/posterior projection. (C) Delayed static images of knees in anterior/posterior and medial/ lateral projections. dislodged during removal, concordant with the imaging findings. A new prosthesis was inserted, and after a short convalescent period, the patient was discharged home.

\section{DISCUSSION}

More than 700,000 total-knee arthroplasties are performed in the United States annually, of which more than one quarter will eventually need revision. The most frequent cause, aseptic loosening, is an inflammatory reaction to the prosthetic components (1). Subsequently, the particulate debris activates tissue phagocytes but cannot be broken down by cellular enzymes. The continued secretion of proinflammatory cytokines and proteolytic enzymes damages the bone and cartilage and further activates immune cells. The heightened inflammatory response leads to osteolysis and, eventually, loosening of the prosthesis (2).

The infection rate after primary total-knee arthroplasty is approximately $1 \%$, but the treatments of aseptic loosening and infected hardware are very different. Therefore, it is extremely important to differentiate them. Often the initial study is a bone scan; however, it has a variable sensitivity of 67\%-100\% for diagnosing an infected knee replacement $(3,4)$.

\section{CONCLUSION}

In this patient, the orthopedic surgeon was clinically concerned about infection and wanted the patient to expeditiously undergo a 1-stop-shop scan to exclude it. We performed the ${ }^{99 m}$ Tc-sulfur colloid scan followed by the ${ }^{111}$ In-labeled leukocyte scan and then the 3-phase bone scan to complete the triple-tracer protocol. This sequence takes the shortest amount of time and has higher accuracy than the bone scan alone (4).

\section{DISCLOSURE}

No potential conflict of interest relevant to this article was reported.

\section{REFERENCES}

1. Rini JN, Bhargava KK, Tronco GG, et al. PET with FDG-labeled leukocytes versus scintigraphy with In-111 oxine-labeled leukocytes for detection of infection. Radiology. 2006;238:978-987.

2. Henkin RE, Bova D, Dillehay GL, et al. Nuclear Medicine. 2nd ed. St. Louis, MO: Mosby; 2006:343-346.

3. Love C, Marwin SE, Palestro CJ. Nuclear medicine and the infected joint replacement. Semin Nucl Med. 2009;39:66-78.

4. Love C, Marwin SE, Tomas MB, et al. Diagnosing infection in the failed joint replacement: a comparison of coincidence detection fluorine-18-FDG and indium111-labeled leukocyte/technetium-99m-sulfur colloid marrow imaging. J Nucl Med. 2004;45:1864-1871. 